Article

\title{
Female Bodies Adrift: Violation of the Female Bodies in Becoming a Subject in the Western Media
}

\author{
Tuija Parikka \\ Department of Mass Communication, St. John's University, New York, 11439, USA; Mail: parikkat@stjohns.edu
}

Submitted: 21 November 2017 | Accepted: 14 June 2018 | Published: 29 June 2018

\begin{abstract}
This article focuses on how the violation of female bodies in the case of mass harassment of women is rendered intelligible by the Western media and the refugees. Violation of female bodies is approached as a site for politicizing possibilities of becoming a subject in the Western media. Informed by Deleuzian notion of "becoming" and the subjectivation of the refugees, I argue that the understanding of "violation" is a central component in contributing to possibilities of becoming affirmed as a subject in the Western media. Empirical material subjected to critical text analysis includes a key text form the Finnish daily newspaper Helsingin Sanomat and refugee interviews. The analysis suggests that the repression of irreducible conceptions of "violation," and the subsequent erasure of the uncertainty of a "self" in the process of becoming, yields to offering possibilities of becoming primarily in Western terms and the affirmation of Western ideological certainty in understanding mass harassment of European women by the refugees.
\end{abstract}

\section{Keywords}

body; mass harassment; media; refugees; subjectivity

\section{Issue}

This article is part of the issue Media and Communication between the Local and the Global, edited by Jessica Gustafsson (Sodertorn University, Sweden) and Kinga Polynczuk-Alenius (University of Helsinki, Finland).

(C) 2018 by the author; licensee Cogitatio (Lisbon, Portugal). This article is licensed under a Creative Commons Attribution 4.0 International License (CC BY).

\section{Introduction}

New Year's Eve celebrations in 2016 were interrupted by an escalating panic caused by women's experiences of becoming a target of mob sexual assaults in various cities in Europe. Mass harassment of European women, or "taharrus gamae" ${ }^{1}$ by the migrants from Northern Africa and Arab countries has resulted in a heightened need for a discourse to construct an interpretation regarding the potential emergence of "sexual terrorism". The violated female body could no longer be imagined as the one "over there" in the Middle East in need of rescue, but "here" in the West as the body which becomes impacted by culture in previously undefined terms. The traditional discursive binaries of the West proved an untenable framework of thinking within which to understand the violation of the female body in the West.
The mediation of the violation of the female body is here approached as a site for politicizing possibilities of becoming as subjects, namely pertaining to the discursive preconditions under which a subject can emerge in highly inflammatory situations. Here, I theorize the connection between the Deleuzian (1995) notion of "becoming" and the subjectivation of the refugees as a process whereby a "self" is under construction by the Western media and argue that rendering "violation" intelligible is a central component in contributing to possibilities of becoming a subject in the Western media. The flexibility of the Western media to reimagine the preconditions of becoming a subject became tested in the mass harassment cases. The empirical material included in this article consists of a key text from the Finnish daily newspaper Helsingin Sanomat (HS), as well as the refugee interpretations of the mass harassment covered by the

\footnotetext{
${ }^{1}$ Mass harassment of women, or "taharrus gamae", is here used as an empirical term referring to the harassment of women by groups of men. The term and the phenomenon are subjected to politicizing, or contestation of meaning concerning an issue (Fraser, 2013), by the media.
} 
Western media. Without the discourse of the previously defined "Other", phenomenon of mass harassment can only be poorly understood. Thus, the aim of the article is to articulate irreducible conceptions of "violation" in acknowledgment of the contemporary uncertainty in understanding mass harassment of women in the West.

In the following, I explore the theoretical connections between subjectivation, bodies and "becoming". I then describe the method of collecting and analyzing the empirical data and subject the key case from HS and the refugee interviews to critical text analysis.

\section{Bodies in Becoming a Subject}

In the context of Europe, the media has traditionally been assessed for its biased representations of migrants who are portrayed as invaders, aliens, or criminals-in short, as a social problem (Binotto, 2010; Bond, Bonsaver, \& Faloppa, 2010; Bruno, 2010). In such portrayals, the media has resorted to identifying foreigners as the enemy and has functioned as the site of social control and the arbitrator of normalcy. When such biased representations align themselves with right-wing agendas (Bond et al., 2010), the media often contributes to the reproduction of relationships of power and racist views (Campani, 2001). For example, in Finland, immigration and Islam merged in the media, especially in 2008 when the right-wing True Finns started to become more popular. Since then, heated debates about multiculturalism, or lack thereof, have been extensively presented by the national media. Many of these debates have focused on honor killings and rapes, resulting in the association of violence and criminality with refugees and Muslims in general (Eide, 2010).

While public discussion connecting gendered violence with "race and ethnicity", in Keskinen's view (2011), is not as polarized in Finland as in some other European countries, rapes of Finnish women by migrant men have resulted in the reproduction of an understanding of migrant male sexuality in particular as threatening. Similarly, many others (Boulila \& Carri, 2017; De Hart, 2017; Jazmati \& Studer, 2017; Pirani \& Smith, 2016) point out the tendencies of public discussion to employ the notions of migrant masculinity as a threat to European women, often in close connection with migration policy debates.

Considering the overall prevalence of criminality discourse in framing the migrants, mass harassment of women by migrants and refugees tests the functioning of democratic media discourses for their capacity to make sense of the complexity of mass harassment as a form of criminality whereby the violation of female bodies becomes negotiated anew. The human body is, after all, the oldest of media, and as such, also a medium of culture (Kraidy, 2013). As a medium of culture, the relationship between the body and culture is often viewed as reciprocal (Durham, 2011). The body is impacting and impacted by culture or shaping and being shaped by cul- ture. The "materiality is the grip of culture on the body" (Bordo, 2003, p. 16, as cited in Durham, 2011) through which culture becomes mediated as culture "takes hold" of a body. The "self" becomes created through such subject positions, or subjectivities, as an embodied experience of culturally specific ways of talking about bodies (Durham, 2011, p. 56). Through the violation of female bodies in mass harassment cases, the bodies function as the socially and culturally constructed medium for politicizing possibilities of becoming a subject.

The Deleuzian notion of "becoming" (Deleuze 1995; May, 2003, p. 144), rather than being-as-difference or identities, serves as a theoretical point of departure in understanding difference in itself. Deleuze invites us to imagine difference as a state: "instead of something distinguished from something else, imagine something that distinguishes itself" (Deleuze, 1995, p. 28, italics added). Difference, then, should not be defined in terms of exclusion, as in an object distinguishing itself from another object by negation; such understanding of difference presumes a pre-constituted identity (Deleuze, 1995, pp. 49-50).

In May's interpretation, "difference lies beneath and within the passing identities to which it gives rise" (2003, p. 144). From this perspective, differences are perceived not in terms of oppositions, as in Subject and its Other. Thus, whenever "bound by a limitation or an opposition", Deleuze invites us to ask what such a situation presupposes in limiting the world of infinite possibilities of becoming (1995, pp. 50-51, 56-57). Instead of reducing difference to an opposition, we should observe difference as differing beyond preconstituted identities that seek to establish limits to the underlying realm of "disparateness".

As the refugees not only claim a material presence in the host countries as groups of people but are also subjected to a constitution of a "self" by the media, "being" a refugee here pertains not only to crossing geographic boundaries but also to discursive borders in the context of the public sphere. Hence, central questions to be asked in this context are: how is "violation", in violation of the female bodies, rendered intelligible in Western media and by the refugees, and subsequently, what kinds of embedded possibilities of becoming a subject through tensions inflicted on and through the body are enabled for women and the refugees by the media? What are the underlying discursive preconditions for a subject to become in this context?

From Deleuze's perspective, deciding problems and affirming differences is a political act; in this process, negation only captures a shadow of a problem, and "is always a reaction, a distortion of a true agent or actor" (1995, p. 268). Decisions regarding the issue of "violation" in the media mark the becoming of an affirmed subject, however distorted that may be.

As almost every nation has non-citizens in their territory who are affected by the ways issues are identified, defined, and mediated, the legitimacy and efficacy of the 
public sphere, in Fraser's view (2007), should be guaranteed by the all-affected principle which requires native citizens to include any affected parties in the public deliberation process, perhaps to acknowledge the multiplicities of possible meanings underlying an issue in the Deleuzian sense.

To address the questions highlighted above, I begin by describing the methodological process undertaken to select and analyze all empirical data, including the key media text and the refugee interviews.

\section{Introduction to the Methodological Background and the Empirical Data}

While this study is predominantly qualitative, a general quantitative overview of the mass harassment debate in the main Finnish daily newspaper $\mathrm{HS}^{2}$ at large was conducted. The purpose of this preliminary step was to get a broad understanding of the scope and content of the mass harassment debate in HS, and primarily to identify key moments in reporting in order to select the key case for closer qualitative analysis.

To collect data on HS coverage of mass harassment cases in Europe over the New Year of 2016, I used the search term "mass harassment" which brought up Cologne and Helsinki cases. Each observation, all from HS, was coded based on location and time: "over there", (12) "over here" (10) or "in-between" (7), between December 31, 2015 and January 23, 2016. Because HS covered the events in Cologne differently from the ones in Helsinki, "location" was included in the coding frame as a variable. In "over there" cases HS reported on mass harassment in Cologne without references to Finland. In "over here" cases HS reported on local (Finnish) investigations on mass harassment in Helsinki. "In-between" reports addressed the factual and/or thematic connection between the events in the context of the two locations. HS reports on Cologne events were typically published in the section for foreign news, whereas HS reports on Helsinki events were domestic, city news, or editorials. The study's time frame excluded reporting which occurred after the immediate news cycle following the events, such as any reports published later on over the course of the spring and summer.

All HS reports on mass harassment were closely read through several times to achieve a general thematic understanding of the coverage of mass harassment discussion at large. Based on descriptive analysis of the coverage, the key moment in the coverage of the events in which politicizing the violation of the female body was identified was intense. The main article "Sexual Harassment is not a Tradition or a Ritual'-According to an Expert, a Distorted Conception of Mass Harassment is Spreading in Europe". (Huusko, 2016) was first published on January 12,2016 , and republished a day later, now titled "The Goal of Mass Harassment is to Isolate Women". This text is the main story to bridge "over there" and "over here" in order to create a space for an "in-between" interpretation in which experts render mass harassment as a form of violation of the female body intelligible in the Western context. Rapidly circulating beliefs regarding "taharrus gamae" on social media prompted the HS to engage in the expert clarification of the nature of mass harassment beyond merely fact-based reporting at a decisive moment in the news cycle.

This key text is subjected to critical text analysis and, as such, grounded in a cultural analysis of the cultural presuppositions it upholds, and the subject positions it thus comes to affirm, through rendering the issue of violation of the female bodies in the context of mass harassment intelligible in the West.

As the Western media has been extensively criticized for its circulation of Othering discourses of the Middle East (Culcasi, 2012; Falah, 2005; Halim \& Meyers, 2010; Hedge, 2011; Parikka, 2015; Pippert, 2003; Said, 1997), this media case is subjected to discussion by the refugees who are vastly affected by the public deliberation of this issue. Their interpretations of the violation of the female body complement the media analysis in this context for how culture shapes the violation of the body.

Thus, one female participant and three men were included in the study. The female participant was from Iran, 24 years old, and was interviewed on July 8, 2016, in Tampere, Finland. The three men, aged 39 years, 38 years, and 27 years, all from Iraq, were interviewed on July 20, 2016, at the reception center for the refugees in Lieksa, Finland. The interviewees were selected based on willingness to participate; a call for participants was announced at the local reception center by Director Tomi Martikainen, and the three Iraqi men volunteered to be interviewed. Similarly, a call for interviewees was circulated through Finnish Immigration Service, Migri, in Tampere, and was responded to by a female migrant from Iran. ${ }^{3}$

All four interviewees identified themselves as Muslims, although the woman was not a believer in her faith. She had arrived in Finland in 2013, married a Finn in 2015, and divorced him a year later. She had studied computer engineering in Iran and later graduated from a professionally oriented university in Finland. The woman, like her siblings, left Iran with the permission of her "openminded" father who had also wished to leave because "open-minded families like these don't really believe in living there because the government is so strict" (F24). Yet the father, to his regret, never left.

The three men had all arrived in Europe either through Greece, before traveling on to Finland, or through the city of Tornio, in the North of Finland, dur-

\footnotetext{
2 HS, as the largest Finnish daily newspaper and as an example of Western media, is included in this research project for its definition power in the context of politicizing mass harassment in Finland.

${ }^{3}$ Regardless of the difference of her status as a migrant, her interview is used in this context due to its relevant contribution to the same issues that the refugees coming from Iraq are discussing. While the number of in-depth interviews conducted is relatively small, the interviewing process reached its saturation point in regards to addressing the key questions at hand.
} 
ing the peak year of refugee flows in 2015. The men were high school graduates, all married with wives and children in Iraq with whom they kept in touch by calling them through Skype, Viber, or by messaging. The circumstances for leaving their country of origin were much harsher for the men than the woman. For one of them (M39), the journey took him through Jordan, Turkey, Greece, Macedonia, Serbia, Croatia, Slovenia, Austria, Germany, Denmark, and Sweden, prior to his arrival in Finland. The ruthlessness of war culture for him consisted of having been betrayed by a member of AlQaeda, posing as his fellow worker at the construction site for Abu Ghraib, which he was building in collaboration with the Americans. This ultimately led to him being kidnapped by Al-Qaeda: "I lost my life then".

The other man (M38), a private security company employee and translator for the US army, had to escape a clan conflict when "another kind of Muslim, Shi'a, asked me to give my daughter for his son...[so] I refused because she was only 13 years old, and Shi'a rules, it is okay that the girl is 10 years old, 11 years old, it is not a problem.... want my daughters to finish their education and to be something important like a doctor or an engineer....After university, they can choose if they want to marry or not".

The third man (M27), a translator for the British in the oil city Al Basra, was aspiring to be a nurse in Finland and had volunteered to help retired people in need in Lieksa. He left Iraq because, having worked with the British, the clan "gave me a paper to fire me from the clan, and this is Iraq, this is our culture, if you are fired from the clan, no one can protect you...not even the government".

During meetings with the interviewees, any acts of influencing their views were avoided while the semistructured interviews were conducted. Similarly, regarding ethnographic sensibilities (Madison, 2005), I intervened as little as possible as they spoke in a narrative form. As a result, they each decided how they chose to frame themselves beyond the most obvious demographic questions, such as name, age, faith, education, country of origin, and their refugee journeys. Beyond the basic background information, reasons for leaving Iraq or Iran and initial impressions of Finland were highlighted. Other issues of interest included the role of media in becoming a refugee, their media use and media criticism in general, as well as reflections on the mass harassment of women on the New Year's Eve 2016, covered by HS. In addition to the HS case, I asked the interviewees to also comment on the case of mass harassment and killing of Farkhunda Malikzada in Kabul, in 2015. Farkhunda Malikzada became a victim of a mob assault, and ultimately killing, having been falsely accused of burning pages of the Quran. This incident was recorded by participants and bystanders by using their cell phones, posted on social media, and later remediated by The New York Times, adjacent to an article, "Flawed Justice after a Mob Killed an Afghan Woman". This case has been analyzed as a media text elsewhere (Parikka, in press) and is only approached here through the interviews. Revisiting this case in this context from the perspective of the refugees is motivated by the inability of the Western media to render the violation of the female body intelligible beyond the construction of it as "incomprehensible" in this case. The refugees' interpretations of it and the New Year's Eve mass harassment case are included for their empirical and heuristic value in making sense of the phenomenon.

When introducing the media cases to the interviewees, I asked them for their views on the violation of the female bodies in conjunction with each of the cases. Here, I will analytically only focus on the interpretations of the violation although each interview as a whole, recorded and transcribed word-by-word as texts, extended from one to almost three hours, and covered a wider range of issues. The transcripts were initially closely read through several times for thematic understanding of the material. Subsequently, analytical attention was focused on sections where the interviewees discussed the two media cases, and more closely, on references, such as hitting, burning, raping, killing, as being constitutive of "violation", which was often empirically framed by defining rights to the female body and its protection (e.g., covering). Similarly, to the critical text analysis of the HS text, the analysis of the interviews as texts places an emphasis on the cultural presuppositions in the service of affirming a "self" through the violation of the female body. The findings emanating from the critical text analysis of the HS case and the interviews cannot be generalized to the refugee and migrant population or media at large due to the small number of cases included here.

Next, I begin the analysis of the empirical data by describing the broader HS coverage of New Year's Eve 2016 mass harassment events first, followed by a critical text analysis of the HS article ("'Sexual Harassment is not a Tradition'...").

\section{Undoing Western Media: From "Taharrus Gamae" to Sexual Harassment of Women in Becoming a Subject}

In the HS reporting of mass harassment of women at large, topics ranged from preventative measures taken in Finland prior to New Year's Eve, reporting of the New Year's Eve events in Cologne, investigation into the potential connection between the two, to the emergence of contradictory information regarding the number and nature of harassment incidents in Helsinki. The number of the cases in the entire sample is 29 in total with the following distribution: "over there" in Cologne (12), "over here" in Helsinki (10), and in-between the two (7).

A close reading of $\mathrm{HS}$ cases addressing harassment in Cologne demonstrates that there are two primary positions for the harassed women and the male migrants: harassed women are predominantly characterized as victims of mass harassment which is set forth by descriptions of them as crying, anxious, and groped women who recount their personal experiences of the events of 
the evening. The male migrants, as perpetrators of harassment, are in several accounts described as drunken masses of foreign men of Northern African or Arab origin and rendered voiceless. According to Jazmati and Studer (2017), a large part of German and other European press reproduced the colonial discourse of "wild North African men" who sexually threaten white European women. In HS, none of the migrants were cited for comments, nor did anyone come forward as a representative of them.

At the onset of HS coverage, the unusually slow media response both in Cologne and Helsinki to the events was reported on by HS, and accusations of deliberate delays emerged. This served as a focal point for bridging harassment cases in Cologne with those in Helsinki: was the lengthy silence regarding the events in Cologne, and extensive police reporting in Helsinki, potentially acting as a political weapon for or against the refugees? HS claims that the news value of the events in Helsinki was limited to the communication coming from the police. Hence, communication from the police set the dominant frame for any subsequent reporting on both cases. Such reporting strives to separate facts from interpretations. This framing was disrupted by remarks from a police officer who referred to the harassment cases as "a new phenomenon in the history of sexual crimes" (Manner, 2016a)-a comment which resulted in contradictory and confusing statements regarding the Helsinki events thereafter. A notable feature of "over here" reporting is the dominant presence of the voices of the police and reporters over any other, including politicians. Interpretations are rarely articulated, with the exception of an Iraqi reporter. The reporter refers to the frustration of drunken young men whose asylum applications have been denied, and who begin to commit sexual crimes (Manner, 2016b).

While the style of reporting remains predominantly cautious and reserved in HS, the newspaper made a decision, as a response to social media flow regarding the issue, to further politicize the violation of the female bodies in the context of the story "Sexual Harassment is not a Tradition'..." which is here subjected to closer critical text analysis.

The article was motivated by a need to address the fear of spreading of "taharrus gamae". "Spreading" suggests the potential discursive dilution of Arab-Europe boundaries, as the "game" is feared to become played upon the female bodies by the refugees in Europe. Along with this "game" and the threat of terrorism, fear, in Melotti's view (2016), is returning to Western countries in general.

How the violation of the female bodies should be understood, with the emerging subject positions, in this HS text is grounded on the rejection of the possibility of non-Western interpretations of "violation." The article claims that the more correct interpretation of the attacks is, rather, that they are sexual harassment or sexual violence. "An understanding of taharrush gamae, circulating in the European media, is a misunderstanding....It is not a ritual or a specific sexual harassment tradition. It is an extreme form of sexual harassment and sexual violence". As such, it is not to be conceived as "planned and organized harassment of women, which is spreading to Europe with the refugees from Arab countries".

Although the article notes that organized and political mass harassment in Egypt is a well-known phenomenon, exemplified by the political nature of mob harassment attacks and rapes during the stepping down of Hosni Mubarak in Cairo in 2011, the increase in sexual harassment of women has occurred in several countries and can be attributed to social, political, cultural, as well as military factors but not religious ones: "large discrepancies between the EU countries can be explained by legal and cultural differences. Different countries have different understanding of what is conceived as sexual harassment....The culture of sexual harassment in the Arab countries cannot be explained by Islam, because commonality of harassment varies between Muslim countries". The HS text refers to the phenomenon of harassment that extends "everywhere" from Egypt, Sweden, and Iraq to Finland as top countries in terms of harassment experienced by women, in that order. The replacement of the notion of a "mass harassment game" with the concept of "sexual harassment/sexual violence", through the establishment of a cultural limitation imposed on any possible Islamic influences of how the "violation" should be rendered intelligible, gives rise to the subjectivation of the refugees and the violated women in ways that are more recognizable within the Western domestic violence discourse. As Bern points out, victimization of women is particularly typical of domestic violence discourses which sidestep the responsibility of the abusers or problems regarding the "social and political context that tolerates and fosters this violence" (2004, pp. 2-3).

Within this discourse, an intelligible rendering of a refugee subject pertains to the reduction of him to Western maleness through his assimilation into the Western drinking culture "over here", with its embedded understanding of maleness as the same: "It seems that [the men] went there to have fun but the situation got out of control....Understanding that harassing women when drunk is fun is of course completely wrong. One should not be naïve and think that it would be acceptable among the migrants either" (Huusko, 2016). Through the mediation of the Western drinking cultures, Middle Eastern maleness can fuse with that of a Western man, and become universalized, "like us"; their behavior is condemned as the behavior of drunken Western men harassing women is condemned, and becoming a victim is understood through risks associated with drunken men who act out of control. The article finds blaming women highly problematic, yet is rendered intelligible on the very same notion it is critical of: sexual harassment of women due to their presence among drunken men in public spaces.

While HS in this case cannot be considered as blatantly emphasizing the association of refugees as sexu- 
ally threatening to white European women, like the media coverage of Cologne events elsewhere in Europe did (Jazmati \& Studer, 2017), the interpretative frames of the events rely on a reductionist Western logic of understanding how gender operates in sexual violence discourse. In this case, Western maleness and femaleness, with its embedded positions in the sexual violence discourse, precedes and sets limitations on the possibility of differentiating, in Deleuzian terms, the act of mass harassment of women in Europe.

How the "violation" of the female body is constituted by the refugees, not in the shadows of the Western media, but through their articulation of a "self" in becoming a subject, is explored next.

\section{Redefining Violation of Female Bodies: "They Don't Like Us"}

Which discursive preconditions underlie the refugees' articulations of a "self" through the violation of the female body in the context of mass harassment cases then? Refugee subjects in becoming assume an alreadythere subject/object positions of the criminality discourse, and firmly reject the reductionist logic of reducing all refugees to such positions. They thus recognize "the thread laid out by identity" in Deleuzian terms (1994, pp. 49-50), which serves as a trajectory for their differing when speaking of a "self" in becoming in regard to the violation of the female body. They acknowledge the threatening nature of the kind of "criminality" that the Finns are "nervous" about: "the people [in Finland] have all the right...to be afraid of refugees" (M39). A male refugee attributes "people not [accepting] us [into the community]" to "bad things" refugees may do: "How shall I say it...they are hitting on the girls, and then for example, and when the girls don't want that, they are forcing them" (M39). Yet the view of a collective subjectivity of the refugees as criminals through the potential violation of the female body is also avoided by the Iraqi and Iranian interviewees, who articulate a "self" as differing from "them/they" as the ones determined by such criminality discourse.

In many instances, the "violation" committed by "them", as mentioned by the interviewees, becomes rendered intelligible by the affirmation of a subject who is presumed to have a right to the female body in Arab/Islamic terms. For example, an Iranian female constructs an understanding of a woman's right to her body and sexuality in terms of her having a right to be protected by a man in Islam. By her account, this is a right that, if given away, is constructed as warranting economic, sexual or other types of punishment. Instead of Muslim women then, she explained that it was not Muslim women but Western women who lacked rights, since "they" are not forced to cover themselves nor are they protected by their family:
They [school teachers] always explained that...women have lots of rights in Islam....

We are under dad's protection, so it is nice someone is protecting us, we don't have to go to work....If the husband lets her work, she can keep all the money for herself, the man is the one who has to pay for all the living and the children, and if the woman does not give sex to the man, he can cut some of the money....It's like a woman's right. And you can be at home with a child, and if the husband hits you, that's fine, you did something bad, he has to, it is the law.... In Islam, it says you have to punish your wife.... always grew up [learning] that Western countries don't care about woman's rights....Like if a woman gets pregnant, the guy can just leave....They don't force women to cover so they show themselves and they are not protected anymore. The woman is protected because family is protection for the woman. (F24)

In her explanation, the woman's right to her own money by her own work precedes her right to her body and sexuality. Furthermore, violation of the female body (e.g., hitting) is in the above quote mandated by Islam. As such, it becomes imagined, not in terms of violence per se, but rather, in terms of protection of the family which is signified as protection of the female body. Thus, punishment is ultimately constructed as imperative for the protection of the female body.

To the extent that "violation" of the female body is conceptualized in terms of protection of the same body, that body is not culturally influenced by victimhood, but rather, the body in terms of requiring containment through its violation:

They [Arab men] do understand that they [women] are allowed to do things here.... They can, for example, stay outside the house at night, go to a restaurant at any time, drink beer and alcohol, spend the night with someone, but the way they are living for some of those people, I am sorry to say but I have to...they think that these are, sorry, bitches, and don't have any manners. We have such people like that....We don't have lots of ladies who can drink in public [in Baghdad]. (M39)

The interviewees argue that Finnish women's liberties are known to the refugees, yet not necessarily fully acknowledged by all. From this perspective, having a right to male protection is non-negotiable for some; in other words, it is construed as imperative of the female "sex"4 as part of a spiritual contract of a kind:

If somebody does not cover herself, for many men, they see that she wants to give it to me. That is why she is not covering, if she wanted to keep it to herself, if she wanted to protect it, she would cover it but now

\footnotetext{
${ }^{4}$ In rape cases, analyzed by Butler, being a property of a man is conceived as an objective of her "sex", and while on the streets, "she is looking to become the property of some other" (Butler, 1995, pp. 52-53).
} 
that she is showing it to me it is like a gift from God to me. So I am allowed to go to her, I am allowed to do whatever I want to do, I can even rape, and my God is fine with it. That is what I see in many places. (F24)

In Soutar's view, covering oneself provides many women a feeling of control over their bodies because it prevents sexual exploitation (2010). The decision to wear one is thus both social and religious (Al-Mahadin, 2013). In the Iraqi and Iranian interviewees' comments above, a "self" is predetermined by spirituality which tracks on the female body and the transformation of its "violation", as understood in Western discourses, into "protection" of family, then a female subject, not as the Other of man, but as a being habituated from the spiritual realm.

Does the positioning of the female body beyond male-female dichotomies also render it beyond something that can be violated as such? In the interviewees' talk, assuming an illegal access to the female body (not granted by the woman's legal family or by disregard of other protective measures as in "God's gifts") is constructed as warranting the ultimate violation of the male body.

Here we have the uimahalli [facility for swimming and saunas]. People go to uimahalli like everyone goes, but they were drunk, and they discovered that no one will stop them if they stepped inside the sauna for the ladies, and they did it, they did it like that....The first one will go and open the door just to see and say aah, and say sorry, and after that the other one will go, and they will make it like, oh we didn't know, but one of them was going like four times, and others were going like six or five....If any one of them did it in Iraq or in Egypt or in Syria or anywhere I think that the family of her will kill him....If she is having her privacy in sauna, for example, and she is, of course, naked because it is sauna, and he is trying to see her naked so if this happened in Iraq you can bet the law will make him like a ball and play with it....I really, really love the law of oriental places...laws must be more strict here. (M39)

In his talk, subjecting the female body to a male gaze without permission is constructed as the ultimate form of violation of her family's rights ("the family of her will kill him"), dishonor, and disrespect, for which the loss of a "self" is deserved, even death. While the "violation" of specifically the female body in terms of violation may be unimaginable here by a "self" in reference to Arab/Islamic terms employed in this discourse, the affirmed subject emanating from this position is rarely truly identified with by the interviewees. Becoming identified by a predetermined subject position through violation of the female body is thus avoided by them throughout, and furthermore, also in the accounts that affirm individuality as ultimately incompatible with Islam.

The Iranian female refers to the case of Farkhunda Malikzada's mob harassment and killing by stating that
"Western laws don't work there [in Afghanistan]", and constructed an account of the fundamental lack of individuality in such societies:

They have a sentence in Farsi: If you don't want to be ashamed of what you are you have to be of the same color as the society.... One person gets up and has an idea that she should be burned-yeah!-and they don't think and they follow the guy next to them because you are going to get punished if you say something else....If somebody is destroying Islam or something similar, people have to gather and fight against it. It is good thing normally, in Islam....People who were born religious, they never had a chance to think individually....Usually, the idea comes from somewhere, like what should we do about it, like some person randomly yells or something-you have to burn-yeah, you have to burn-something similar to that....a lot of these things, a lot of that happens. (F24)

Khazaal (2017) maintains that the Arab states, in general, do not recognize nonreligious identity for Arabs; any allegations of leaving Islam result in violence, including mob killings and other forms of violence. In his view, there is no place for an individual in the community of believers who is rather perceived as a disturber of collective harmony, or a collective body. The Iranian interviewee (F24) recalled another video, similar to Farkhunda Malikzada's, of the killing of a daughter whose father had been enraged having found out about her boyfriend. The notion that "they don't see this really as violence, but as the defense of what they believe" (F24) is also constructed by another interviewee:

They cannot think about it with their head, they think by hand first, they don't care, it is very easy, this woman, she burned the Quran, that's it. They don't ask you why you did it....In Afghanistan especially, it is about Islam and Quran: no one (including the police) can help in this case. (M38)

The female body in the accounts above is not granted individual subjectivity required for its violation, and subsequently, the status of victimhood. Instead, the female body yields to the confirmation of collective (male) subjectivity. Both possibilities of perceiving the female body, as being beyond violation, or alternatively, as being violated, in the mass harassment cases are indeed realized by the Iraqi and Iranian interviewees, yet transcended without reducing a "self" to one position or another: their self-positioning does not align with either Arab/Islamic or Western terms, nor can they be interpreted in dichotomous or straightforward ways. As they do not necessarily identify with a particular subject position prescribed for a collective or an individualized subject through a specific understanding of "violation", they retain a possibility of shifting positions in becom- 
ing in this context. Thus, the Iraqi and Iranian interviewees themselves remain in a state of distinguishing himself/herself, in Deleuzian terms, to not to become "distorted" as subjects in becoming.

\section{Conclusion: Female Bodies Adrift}

The mediation of the violation of the female body in the context of mass harassment of women in Europe is here approached as a site for politicizing possibilities of becoming subjects. How "violation" is rendered intelligible is a central component in contributing to possibilities of becoming affirmed as a subject in the Western media. By enforcing an understanding of violation of female bodies, in the cases of mass attacks in Cologne, within a Western sexual violence discourse with its subject-object positions instead of mass harassment (a game), HS contributed to the organization of a relatively vulnerable subject position for a female victim of sexual violence in the hands of refugee males. The refugees' acts are rendered intelligible through the lens of Western drinking cultures, as they become identified universally as the same. Establishment of universal maleness in Western terms is in this context set forth through limitations imposed on the possibility of any Arab/Islamic influences in understanding "violation".

What is signified as "violation" by the Western media is not constructed as such by the refugees in the context of their interpretations of the harassment cases discussed here. In these interpretations, the female body functions beyond such subject-object, perpetratorvictim, dichotomies, and is not understood in relation to the terms that would specifically render it as "violable"; it is rather imagined as something that is preceded by the family's rights to the body and its protection, which when left unprotected (as in God's gifts), can be constructed as accessible as opposed to violated per se, or punishable (as in Farkhunda Malikzada's case) in the establishment of a collective subjectivity. How to imagine female bodies beyond predetermined positioning remains unarticulated, and as such adrift.

Articulations of "violation" of the female bodies by the refugees, as irreducible to the Western meanings, yet intelligible, become erased by the Western media through the erasure of mass harassment discourse with its possibilities of signification of collective subjectivity beyond the Western sexual violence discourse. Hence, understanding "violation" is a central component in contributing to possibilities of becoming a subject in the Western media: the female body is not constructed as violated in the same way if impacted by other than merely Western influences. From this perspective, the Western media can construct possibilities of becoming a subject for women and refugees by curbing differing and offering stable identities, and an understanding of "unity", when there are none. Becoming a subject, in other words, is predominantly enabled in relation to a relatively unchanging understanding of universal male- ness and femaleness, and the relationship between the two in Western terms that the refugees can identify with. Refugees involved in mass harassment attacks, as covered by the HS, were not subjected to vilification in a similar vein as some other European media, and yet, the complexity of the issue remains unaddressed. The realm of Deleuzian "disparateness" that underlie the possibilities of becoming a subject in mass harassment cases remains repressed. This compromises various possibilities of affirming a "self" in the process of becoming, in all of its uncertainty in-between Western and Arab/Islamic influences. Controlling the understanding of "violence" is a key precondition for "stifling" the process of becoming, or movement of meaning. Deliberation, by Fraserian allaffected parties, of what it means to violate someone becomes limited by the establishment of the preconceived certainty of Western ideologies.

As it is, the mainstream media offers possibilities for re-organization of the terms of becoming as subjects for women and the refugees rather cautiously in this context. This does not, however, determine the positionality of the refugees themselves who, while making sense of "violation", remain "elsewhere" beyond subject positions set forth by these discourses under construction, and thus retain an unfixed "self" in relation to, but also beyond, the oppressive regimes of bodily violence of the Islamic world (Khazaal, 2017) and the reductionist logic of many Western media discourses that may seek to "Other" the migrants on the one hand, but also reproduce the migrant "self" within the unity of Western "sameness" on the other. Voices that are not solely articulated through individuality nor collective subjectivity, but perhaps by Deleuzian radiuses of terms, are critical to contemporary challenges of understanding mass harassment of women in the West.

\section{Acknowledgments}

I am thoroughly indebted to remarkable anonymous reviewers who from different angles provided the kind of criticism that significantly contributed to this project. I am also grateful to have had the opportunity to benefit from astute observations and suggestions of the academic editors, Jessica Gustafsson and Kinga PolynczukAlenius, as well as from productive exchanges with a conference opponent for this paper, Poul Erik Nielsen, in the summer of 2017. Director Tomi Martikainen at the Märäjälahti Reception Center in Lieksa, Finland, allowed me numerous unhurried visits to the Center to learn about the life at the facility from its staff and residents for which I am profoundly thankful. My deepest gratitude, however, must be expressed to the interviewees. Without their generosity to discuss difficult and sensitive matters with me, this paper would have remained severely partial. This project has received financial support in the form of the Summer Support of Research Grant from St. John's University. 


\section{Conflict of Interests}

The author declares no conflict of interests.

\section{References}

Al-Mahadin, S. (2013). Arab feminist media studies: Towards a poetics of diversity. In L. McLaughlin \& C. Carter (Eds.), Current perspectives in feminist media studies (pp. 5-10). London and New York, NY: Routledge.

Bern, N. (2004). Framing the victim. Domestic violence, media, and social problems. Hawthorne: Aldine de Gruyter.

Binotto, M. (2010). Invaders, aliens, and criminals. Metaphors and spaces in the media definition of migration and security policies. In E. Bond, G. Bonsaver, \& F. Faloppa (Eds.), Destination Italy: Representing migration in contemporary media and narrative (pp. 31-58). Bern: Peter Lang.

Bond, E., Bonsaver, G., \& Faloppa, F. (Eds.). (2010). Destination Italy: Representing migration in contemporary media and narrative. Bern: Peter Lang.

Boulila, S. C., \& Carri, C. (2017). On Cologne: Gender, migration, and unacknowledged racisms in Germany. European Journal of Women's Studies, 24(3), 286-293.

Bruno, M. (2010). The journalistic construction of "emergenza Lampedusa": The Arab Spring and the "landings" issue in media representations of migration. In E. Bond, G. Bonsaver, \& F. Faloppa (Eds.), Destination Italy: Representing migration in contemporary media and narrative (pp. 59-84). Bern: Peter Lang.

Butler, J. (1995). Contingent foundations. In S. Benhabib, J. Butler, D. Cornell, \& N. Fraser (Eds.), Feminist contentions. A philosophical exchange (pp. 35-58). New York, NY: Routledge.

Campani, G. (2001). Migrants and media: The Italian case. In R. King \& N. Wood (Eds.), Media and migration: Constructions of mobility and difference (pp. 38-52) . New York, NY: Routledge.

Culcasi, K. (2012). Mapping the Middle East from within: (Counter)cartographies of an imperialist construction. Antipode, 44(4), 1099-1118.

Deleuze, G. (1995). Difference and repetition. New York, NY: Columbia University Press.

Durham, G. M. (2011). Body matters: Resuscitating the corporeal in a new media environment. Feminist Media Studies, 11(1), 53-60.

Eide, E. (2010). Media in motion: Cultural complexity and migration in the Nordic region. New York, NY: Routledge.

Falah, G. W. (2005). The visual representation of Muslim/Arab women in daily newspapers in the United States. In G. W. Falah \& C. Nagel (Eds.), Geographies of Muslim women: Gender, religion, space (pp. 300-320). New York, NY: Guilford Press.

Fraser, N. (2007). Transnationalizing the public sphere.
On the legitimacy and efficacy of public opinion in a Post-Westphalian world. Theory, Culture \& Society, 24(4), 7-30.

Fraser, N. (2013). Fortunes of feminism. From statemanaged capitalism to neo-liberal crisis. London: Verso.

Halim, S., \& Meyers, M. (2010). News coverage of violence against Muslim women: A view from the Arabian Gulf. Communication, Culture \& Critique, 3(1), 85-104.

De Hart, B. (2017). Sexuality, race, and masculinity in Europe's refugee crisis. In C. Crutters, S. Mantu, \& P. Minderhound (Eds.), Migration on the move: essays on the dynamics of migration (pp. 27-53). Leiden: Brill.

Hedge, R. S. (Ed.). (2011). Circuits of visibility: Gender and transnational media culture. New York, NY: New York University Press.

Huusko, J. (2016, January 12). "Sexual Harassment is not a Tradition or a Ritual"-According to an Expert, a Distorted Conception of Mass Harassment is Spreading in Europe. Helsingin Sanomat. Retrieved from https://www.hs.fi/ulkomaat/art-2000002879553.html

Jazmati, Z., \& Studer, N. (2017). Racializing “Oriental” manliness. From colonial contexts to Cologne. Islamophobia Studies Journal, 4(1), 87-100.

Keskinen, S. (2011). Borders of the Finnish nations: Media, politics, and rape by "foreign perpetrators". In E. Eide \& K. Nikunen (Eds.), Media in motion. Cultural complexity and migration in the Nordic region (pp. 107-124). London and New York, NY: Routledge.

Khazaal, N. (2017). The cultural politics of religious defiance in Islam: How pseudonyms and media can destigmatize. Communication and Critical/Cultural Studies, 14(3), 271-287.

Kraidy, M. (2013). The body as medium in the digital age: Challenges and opportunities. Communication and Critical/Cultural Studies, 10(2/3), 285-290.

Madison, S. D. (2005). Critical ethnography: Methods, ethics, and performance. London: Sage.

Manner, M. (2016a, January 9). Assistant Chief of Helsinki Police for a British paper: Unprecedented sexual harassment over the New Year. Helsingin Sanomat. Retrieved from https://www.hs.fi/ kaupunki/art-2000002878942.html

Manner, M. (2016b, January 7). Iraqi reporter living in Finland: Helsinki gathering unlikely to have a connection to troubles in Cologne. Helsingin Sanomat. Retrieved from https://www.hs.fi/kaupunki/art-200 0002878649.html

May, T. (2003). When is the Deleuzian becoming? Continental Philosophy Review, 36, 139-153.

Melotti, M. (2016). The carnival of fears: The 2016 violence in Cologne. In B. M Pirani \& T. S. Smith (Eds.), Embodiment and cultural differences (pp. 132-146). Cambridge: Cambridge Scholar Publishing.

Parikka, T. (2015). Globalization, gender, and media. Formations of the sexual and violence in understanding 
globalization. Lanham and London: Lexington Books. Parikka, T. (in press). The female body in global media. In M. Juergensmeyer, S. Sassen, \& M. Steger (Eds.), The Oxford handbook of global studies. New York, NY, and Oxford: Oxford University Press.

Pippert, W. (2003). Media coverage of Arabs and Arab Americans. In F. Cropp, C. Frisby, \& H. Mills (Eds.), Journalism across cultures (pp. 65-78). lowa, IA: lowa State Press.
Pirani, B. M., \& Smith, T. S. (Eds.). (2016). Embodiment and cultural differences. Cambridge: Cambridge Scholar Publishing.

Said, E. (1997). Covering Islam: How the media and the experts determine how we see the rest of the world. New York, NY: Pantheon Books.

Soutar, L. (2010). British female converts to Islam: Choosing Islam as a rejection of individualism. Language and Intercultural Communication, 10(1), 3-16.

\section{About the Author}

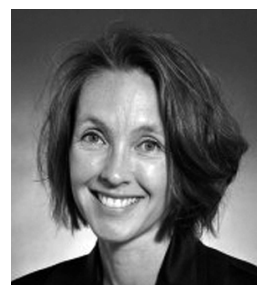

Dr. Parikka is an assistant professor of communication arts at St. John's University, USA. Her research focuses on the relationship between globalization, gender, and media, examined in her most recent title, Globalization, Gender, and Media: Formations of the Sexual and Violence in Understanding Globalization (2015), as well as in a book chapter, "The Female Body in Global Media", for the Oxford Handbook of Global Studies (in press). Her current research extends the scope of her earlier research to migration and digital media which she is now working on as a visiting fellow at the London School of Economics and Political Science. 